\title{
РЕФЛЕКСИВНИЯТ ПОДХОД ПРИ ФОРМИРАНЕ НА ЛИЧНОСТНИ И СОЦИАЛНИ КОМПЕТЕНТНОСТИ ЧРЕЗ УЧЕБНО СЬДЬРЖАНИЕ В КОНТЕКСТА НА БЕЖАНСКАТА ПРОБЛЕМАТИКА
}

Проф. д.п.н. Сийка Чавдарова-Костова

Софийски университет „Св. Климент Охридски“

\begin{abstract}
Резюме. Съвременно предизвикателство пред български учители е представянето на учебно съдържание, свързано с бежанските потоци, и формиране на личностни и социални компетентности в контекста на интеркултурното образование и възпитание с насоченост към осъзнаване на значимостта на темата за миграциите в индивидуален, общностен, национален и международен контекст. Рефлексивният подход се оказва изключително подходящ за осмисляне на значимостта на такъв тип знание от гледна точка на глобалните миграционни процеси не само от страна на учениците, но и от страна на учителите, които разполагат с богатство от възможности за информиране децата и развитие на нагласи към проблематиката в рамките на урочна дейност, час на класа, извънкласни и извънучилищни дейности.

Ключови думи: личности и социални компетентности; бежанци; рефлексия
\end{abstract}

През последните няколко десетилетия дискусията относно значимостта на индивидуалното и социалното в процеса на развитие на личността се характеризира с неравномерност, както на образователно-политическо ниво, така и на теоретично-методологическо. Дисбалансът в полза на индивидуалното пренебрегва неговата детерминираност от социалните условия, в рамките на които се случва личностното развитие, а дисбалансът в полза на социалното ограничава възможностите за изява на личностната мотивираност, интереси, способност. Ето защо е нужно съществуващите дисбаланси да бъдат преодолени, така че да се постигне по-голяма хармония в процеса на развитие на личността.

Преди повече от десетина години личностната компетентност с наименование „Автономно действане“ е заложена в една от компетентностите категории при комплекса от ключови компетентности, разработени от OECD 
(Организация за икономическо сътрудничество и развитие). При аргументацията за необходимостта от нейното формиране специално се подчертава връзката индивидуално - сочиално: „Автономното действане не означава функциониране в социална изолация. (...) То изисква индивидите да имат възможност да управляват техния живот по един значим и отговорен начин чрез упражняване на контрол върху тяхното живеене и работни условия. Индивидите трябва да действат автономно, за да участват ефективно в развитието на обществото и да функционират добре в различни житейски сфери, в т.ч. работното място, семейния и социалния живот“. Автономното действане предполага съпоставяне между решенията и действията, които индивидът предприема по отношение на съществуващите социални норми, взаимодействие с различни социални институции, отражението на миналото върху настоящето. Тази компетентност изисква и формиране на „способността да се отстояват права, интереси, граници и нужди“, „да се формират и ръководят житейски и личностни планове“. Това е необходимо за развитието на „независима идентичност“" и умението за правене на избори от страна на индивидите, а не „просто да следват тълпата““, като се цели да бъде формирана „потребност от рефлектиране върху техните ценности и техните действия“"1). Акцентът в последното изречение пряко насочва вниманието върху формираността на личностна рефлексия, в основата на която стои самопознанието, като: „В ролята на инструмент посредник се оказват както знанията за личността, така и реалните дейности, в които е включена личността и чрез които тя се формира, изучавайки се, и се самоизучава, формирайки се“" (Vasilev \& Djaldeti 2018, 27).

Красноречива илюстрация на ангажираността на образователно-политическо ниво в рамките на Европейския съюз е извършената през 2018 г. актуализация на ключовите компетентности за учене през целия живот и наименованието на една от тях, а именно - „Личностна компетентност, социална компетентност и компетентност за придобиване на умения за учене“б2). Тя доразвива петата компетентност от първата рамка на ключовите компетентности от 2006 г., насочена към ,ученето да се учи“3). Внимателният прочит на съдържанието на компетентността позволява открояването на основните акценти на разбирането за „личностна компетентност“ и „социална компетентност“ като очаквания спрямо формирането им у гражданите на Европейския съюз. Посочва се, че това е „способността човек да разсъждава за себе си, да управлява ефективно времето и информацията, да работи конструктивно с други хора, да запазва своята устойчивост и да управлява собственото си учене и кариера“, което „включва способност за справяне с несигурността и сложността, за придобиване на умения за учене, за подпомагане на собственото физическо и емоционално благосъстояние, за поддържане на физическото и психичното здраве, за воденето на здравословно осъзнат и ориентиран към бъдещето начин на живот, за съпричастност и за управление на конфликти в 
един приобщаващ и подкрепящ контекст“. Интересен факт е, че в представения текст има общо дефиниране на цялата компетентност, т.е. налице е едно своеобразно смесване на съдържанието на личностно и сочиално, въпреки че акцентьт по-скоро е върху формирането на личностни качества с оглед ежедневните потребности за съвместен живот в обществото. Тази насоченост намира своето обяснение по-нататък, където се отбелязва, че: „За успешни междуличностни отношения и социално участие е от съществено значение разбирането на кодексите на поведение и правилата за общуване, общоприети в различните общества и среди“. В допълнение се посочва необходимостта от развитие на „способността за учене и работа както в сътрудничество, така и самостоятелно“ и децата да бъдат възпитавани „да могат да общуват конструктивно в различни среди, да работят съвместно с други хора в екип и да преговарят“, като демонстрират „толерантност, изразяване и разбиране на различни гледни точки, както и способност за вдъхване на доверие и за съпричастност“. Посочените желани личностни качества се очаква да „се основават на нагласа за сътрудничество, отстояване и почтеност“, включвайки „уважаване на различността на другите и на техните нужди, както и готовност за преодоляване на предразсъдъци и за постигане на компромис“(4).

Отбелязаното дотук показва пряка насоченост към основните характеристики на интеркултурната компетентност, формирането на която е една от основните задачи на съвременната педагогика, отчитаща живеенето в динамичен свят на многообразие от културни идентичности. Неслучайно една от основните характеристики на интеркултурната компетентност е т.нар. „гъвкавост на поведението“, която предполага „способността да се адаптира поведението към различни изисквания и ситуации“, както и способността за „адаптиране към обичаите, навиците на другите хора“, за „приемане на помалко познати начини на работа“, което би довело до увеличаване на проявите на доброжелателност ${ }^{5)}$. Посоченото важи както за хора, които трябва да се адаптират към нови за тях условия на живот, каквито са мигрантите, в т.ч. търсещите международна закрила, така и хората от приемащото общество, които трябва да се приемат, че ще живеят съвместно с новодошлите. Понякога тези процеси протичат като преживяване на необходимостта от решаване на проблеми в ежедневието, което „подпомага както процеса на учене, така и способността на човек да се справя с препятствията и промените“ посредством „прилагане на придобити по-рано знания и житейски опит, както и любопитство за търсене на възможности за учене и развитие в различни жизнени контексти“"6).

На базата на всичко, посочено дотук, личностната и социалната компетентност могат да бъдат разгледани в контекста на една „междукултурна рефлексия“, интерпретирана като „процес на осъзнаване, самооценка и саморегулация на образователния субект в конкретен тип и вид образователна 
институция и конкретното населено място, отчитайки маркерите на езиковото, демографското, географското, етническото, екологичното и друг тип многообразие“" (Koleva 2011). Такъв тип рефлексия синтезира в себе си както различни аспекти на идентичността, така и отчита влиянието на важни социилни детерминанти на личностното формиране, които би трябвало да се вземат предвид при планирането и организирането на възпитателни дейности в училищна среда.

В тази насока могат да бъдат очертани два основни пункта:

- познаване от страна на учителите на нормативните документи, които дават възможностите (и границите) за осъществяване на реална практическа педагогическа дейност в класните стаи и/или извън тях;

- методическа подготвеност, в т.ч. организационна компетентност на учителите за реализиране на дейности за формиране на личностни и сочиални компетентности в контекста на интеркултурното образование/възпитание, в т.ч. чрез тематика, свързана с процеса на интеграцията на хората със статут на бежанци в приемащото общество.

Ключов нормативен документ в тази насока за българските учители е Наредба № 13 за гражданското, здравното, екологичното и интеркултурното образование. Особено релевантни по отношение интегриране на бежанската проблематика в училищни дейности са две от основните тематични области, посочени в чл. 11: „толерантност и интеркултурен диалог“ (с минимален брой за осъществяване в час на класа по един час за класове I - IV, VIII - XII и по два часа за класове V - VII) и „превенция на насилието, справяне с гнева и агресията и мирно решаване на конфликти“ (с минимален брой за осъществяване в час на класа по един час за класове I - IV и по два часа за класове $\mathrm{V}$ - XII). Именно в подбора на теми и разпределението им по класове може да се прояви организационната компетентност на учителя, който трябва да отчита изискването за посочения минимален брой задължителни часове, имайки предвид и възможността педагогическият съвет в контекста на ,училищната стратегия и училищните политики (...) да определя приоритетни тематични области“ „съобразно спецификата на общността, средата, интересите и възрастовите особености на учениците“. Учителят би могъл да разчита и на компетентността на гост-лектори от различни институции и неправителствени организации, които могат да работят с децата в негово присъствие ${ }^{7)}$.

Организационната компетентност на учителя е в помощ на методическата му компетентност, която, от своя страна, е пряко свързана с уменията му да приложи рефлексивния подход при представяне на учебно съдържание, свързано с проблематика за бежаничите, особено когато за повечето от децата в училище (каквато е ситуацията в България) това не е лично преживяна тема, свързана с потребностите на ежедневието им. В тази насока своята несъмнена полезност имат учебните материали за различни възрастови групи, 
разработени от Върховния комисариат за бежанците към ООН, достъпни вече и на български език за всеки български учител. В тези материали има редица възможности за рефлексия от страна на учениците по отношение причините за присъствието на бежанци в приемащите общества, изпитваните от тях чувства в прочеса на адаптация и интеграция и др. Прилагането на рефлексивния подход се оказва изключително подходящо за формирането и на личностни, и на социални компетентности чрез такова учебно съдържание, тъй като през осъзнаването и осмислянето се достига до сочиалната детерминираност, но и се развиват личностно отношение и нагласи към групата на бежаничте.

Представянето на някои конкретни примери, особено подходящи за прилагане на рефлексивния подход в практически ориентирани ситуации, е своеобразна илюстрация на казаното. Едно от упражненията за деца от възрастова група 6 - 9 години е с основен метод дискусия, насочена към осмисляне на това „какво е да си нов ученик в ново училище, когато току-що си пристигнал в държавата“" (подходящо не само за деца бежанци, но и за деца мигранти извън тази категория). Препоръчва се „децата да изберат темите, по които искат да получат насоки“. Такива теми могат „да са свързани с: какво трябва да правиш, когато влезеш в класната стая, какво трябва да правиш, когато си в междучасие, какво трябва да носиш в училище и др.“. Децата от класа „могат да съставят указания със снимки“ с цел по-добра ориентация на новодошлите в класа и училището ${ }^{8}$. Такъв тип дейности, насочени към улесняване адаптацията на деца от други държави, всъщност съдействат за осъзнаване смисъла на дейности извън прочеса на обучение, които ежедневно са извършвани в училищното пространство, не само отразяващчи сощииалната роля на ученик, но и социокултурно детерминираните ѝ параметри, които най-вероятно дори не са премисляни като такива от малките деца.

Следващият пример за предлагано упражнение за същата възрастова група, насочено към ,улесняване на взаимоотношенията между децата и осъзнаване на културното разнообразие на индивидуално ниво“ е една от срещаните и в други системи за интеркултурно образование дейности, свързана със смисъла, който носи името на човека. Наименованието на упражнението е „Разкажи ми повече за името си“, като на децата се дава за домашна работа „когато се приберат вкъщи, да разпитат какво е значението на тяхното име, на имената на братята, сестрите или родителите им, какъв е произходът на имената им и дали има други хора в семейството със същото име“. Ако азбуката, която е в основата на писмеността на съответния език, е друга, тогава на децата се дава задачата да помолят родителите си да им изпишат имената по нея. След това в класната стая се предлага интерактивна дейност, при която „в крьг или по двойки децата могат да зададат следните въпроси на своите другарчета в класната стая: „Как се казваш?“, „Откъде идва името ти?“, „Какво означа- 
ва?“. Препоръчва се учителят да представи „имената на децата на различни езици (напр. Петър, Пиер, Питър)“ и да ги попита „дали познават деца от същия клас, випуск или училище с име, което е различно, но има същия корен“. Други дейности, които се посочват като възможни, са разглеждане начина на изписване на имената с букви от различни азбуки, както и опитване за изписването им в класната стая, рисуване на картина, изобразяваща своето име, и показването ѝ на останалите деца ${ }^{9}$. Всяка една от тези дейности несъмнено развива както личностна, така и социална компетентност, изисквайки съответна рефлексивност от страна на децата. През предизвикването на интерес към личното име на връстника, което е носител на неговата различност, всъщност се постига и осъзнаване на тази различност в сравнението ѝ със своята. От педагогическата компетентност на учителя в областта на интеркултурното възпитание зависи в каква степен той би извлякъл оптимална полезност от такъв тип дейности, тъй като чрез името той би могъл да премине през осъзнаване на чуждата и своята социокултурна идентичност в разнообразието от нейни проявления - етническа, национална, религиозна, полова и др., което е от изключителна значимост с оглед реализацията на приобщаващото образование (Chavdarova-Kostova 2019).

В учебните материали има и други предложения за дейности, които са подходящи за реализиране на рефлексивния подход в час на класа, напр. ,за запознаване и приемане на разнообразието в различните култури и държави“. При това упражнение се препоръчва да бъдат демонстрирани различни начини за поздравяване в съответни култури или държави чрез заставане в роли на поздравяващи, в т.ч. по двойки (както децата, така и учителите). Рефлексивността се въвежда чрез разговор с децата относно сходствата и различията, които те са уловили при представянето на различните видове поздрави, в т.ч. чрез въпрос ,дали имат любим поздрав““. Съобразено с възрастовите особености на децата е и упражнението с наименование „Игри от целия свят“, при което децата се разделят на малки групи, в които се представят игри от различни краища на света, след което те ги играят. Рефлексивният подход се прилага в края, когато децата дискутират в каква степен „тези игри приличат на игри, които са играли преди““10). По този начин, чрез въвеждане на сравнението, което е основен метод, използван в интеркултурното образование и възпитание с цел откриване на различия, но и на сходства, се постига осъзнаване на еднаквостта на потребностите и изпитвани чувства при реализация на игра (в случая - възрастово детерминирани), което е предпоставка за приемане на различния като сходен. Типичен пример в посочената насока е упражнение, при което се цели опознаване на чужди култури чрез елементи на ежедневната им идентичност, каквато е храната. Учениците се разделят на малки групи, в които обсъждат „какво закусват обикновено“, след което се организира дискусия в класа. Оформя 
се списък с представените храни, като децата трябва да изпишат рецептите за приготвянето им и след това ги закачат на стената и всеки получава копие. При възможност може да се организира приготвяне на закуска в училище с цел практическо упражняване ${ }^{11)}$.

Всички представени дотук конкретни примери за работа с деца в начална училищна възраст са насочени към осъзнаване на различията, но и рефлексия върху собствената културна идентичност на базата на културни елементи, типични за ежедневието и възрастта на децата. Прилагането на такива и други дейности от учителя изисква методическа компетентност в областта на интеркултурното образование и възпитание не само на ниво знания за възможни методи, средства, подходи, но и за прилагане на рефлексия и саморефлексия в дейностите, доколкото те са свързани с личностната идентичност на всеки, включен в тях (самата тя детерминирана социокултурно).

Формирането на социални компетентности предполага дейности, които ангажират общността в различните измерения на това понятие - както местна/локална общност на приемащото общество, така и семейната общност и общността на група бежанци, които имат еднаква националност и/или етническа група. Оптималната социална интеграция предполага създаването на условия за среща на тези две основни групи общности, в т.ч. чрез организирана педагогическа дейност. Именно това е основание да се препоръчва на училищата да организират дейности, като бъдат канени семействата на децата бежанци с цел постигане на съпричастност, напр. „предприемане на съвместна творческа дейност по темата за бежанците и споделяне на начинанието с тяхната общност например чрез покана на родителите или изнасяне на представление пред училището или пред други класове“" във варианти като „организиране и провеждане на изложба“, „организиране на концерт с танци или игри“" и др. ${ }^{12)}$.

Особено подходящи за развитие на социални компетентности се оказват предложения за възрастта 12 - 15 години, които предполагат както в по-голяма степен рационалност от страна на учениците по отношение на информация за мигранти, търсещи убежище, бежанци, до която те могат да достигнат чрез масмедии, но и посредством контакти с работещи с тази категория хора, както и при възможност, чрез лични впечатления. Едно от упражненията, препоръчвани за тази възрастова група, е свързано с насочване на децата към „подходящи статии“ и проучване на „местни медии; местни общностни групи; приемателни центрове; организации, които помагат на бежанци и лица без гражданство“ с цел установяване на основните „сфери, в които бежанците или лицата без гражданство могат да получат правна или практическа помощ“. Очакваният резултат от такъв тип дейности е изцяло в контекста на рефлексивността: „Осъзнаване на възможността на всеки човек да въздейства на обществото и върху живота на други хора““13). Тук ясно могат да бъдат 
откроени двете основни компетентности - личностната и социалната, пречупени през призмата на рефлексията върху собствените възможсности за оказване на помощ на другите, което вече насочва към социалния аспект като резултат именно от тази рефлексивност (съчетан със социално значима прагматичност - въздействие върху другите в социално желан план).

В края на статията ще бъде представен пример на упражнение за възрастова група 15 - 18 години, при което основна задача е разсъждаване върху въпроса „Факти, измислици или нещо по средата?“. Препоръчва се осъществяване на групова работа по „конфликт, който се тиражира в медиите в момента и вследствие на който са се появили бежанци, търсещи закрила, или лица без гражданство“, като учениците избират информация от медиите и разглеждат конфликта от гледна точка на източника. След това се организира дебат, в който се представят различните интерпретации на информацията по съответния казус. Ключов момент в тази дейност е обсъждането на „достоверността на установените източници“ - един изключително актуален нюанс в контекста на проблематиката за „фалшивите новини“. На учениците се препоръчват достоверни източници на информация като уебсайта на Върховния комисар за бежанците към ООН. Като резултат от дейността се посочва: „Разбиране относно различните начини, по които може да се представя информацията, както и относно възможността за използване на подвеждаща и невярна информация от медиите. Насърчаване на критичното мислене“б4).

Макар и малко, няколкото примера от учебни материали, предназначени за деца от различни възрастови групи за осъзнаване на различността на бежанците, живеещи в приемащите общества, илюстрират красноречиво възможности за формиране на личностни и социални компетентности в училищна среда. Спецификата на тази проблематика, характеризираща се със сензитивност, деликатност, проява на разбиране към културната различност на базата на осъзнаването ѝ, естествено припознава рефлексивния подход като основна методология за организиране на педагогически дейности в контекста на формирането на интеркултурна компетентност. Практическото им осъществяване обаче изисква добра методическа компетентност на учителите, предполагаща съответна ангажираност от висшите училища, подготвящи педагогически кадри - една перспектива, която заслужава да бъде развита.

\section{БЕЛЕЖКИ}

1. The definition and selection of key competencies. Executive Summary. OECD, c. $14-15$.

2. Препорька на Съвета от 22 май 2018 година относно ключовите компетентности за учене през целия живот. Официален вестник на Европейския 
съюз. 4.6.2018 г. - https://eur-lex.europa.eu/legal-content/BG/TXT/PDF/?uri= CELEX:32018H0604(01)\&from=EN, 13.05.2021.

3. Key Competences for Lifelong Learning. European Reference Framework. European Communities, Luxembourg, 2007.

4. Препоръка на Съвета от 22 май 2018 година относно ключовите компетентности за учене през целия живот. Официален вестник на Европейския съюз. 4.6.2018 г. - https://eur-lex.europa.eu/legal-content/BG/TXT/PDF/?uri= CELEX:32018H0604(01)\&from=EN, 13.05.2021.

5. Intercultural competence assessment (INCA). Assessor manual (2004). INCA, LdVII, 2004, c. 5 - 6.

6. Препоръка на Съвета от 22 май 2018 година относно ключовите компетентности за учене през целия живот. Официален вестник на Европейския съюз. 4.6.2018 г. - https://eur-lex.europa.eu/legal-content/BG/TXT/PDF/?uri= CELEX:32018H0604(01)\&from=EN, 13.05.2021.

7. Наредба № 13 за гражданското, здравното, екологичното и интеркултурното образование - https://www.mon.bg/bg/59, 13.05.2021.

8. Да преподаваме за бежанците. Възраст 6 - 9. Ръководство за упражнения. ВКБООН, 2017. - https:/www.unhcr.org/bg/wp-content/uploads/ sites/18/2019/02/BG_PDF_6-9_Activity_Guide1.pdf, 13.05.2021, c. 2.

9. Да преподаваме за бежанците. Възраст 6 - 9. Основен учебен план. ВКБОOH, 2017. - https://www.unhcr.org/bg/wp-content/uploads/sites/18/2019/02/ BG_PDF_6-9_Primary_Curriculum1.pdf, 13.05.2021, c.4 - 5.

10. Пак там, $6-7$.

11. Да преподаваме за бежанците. Възраст 9 - 12. Ръководство за упражнения. ВКБООН, 2017 - https://www.unhcr.org/bg/wp-content/uploads/ sites/18/2019/02/BG_PDF_9-12-Activity_Guide1.pdf, 13.05.2021, c. 4 - 5.

12. Пак там, с. 4.

13. Да преподаваме за бежанците. Възраст 12 - 15. Ръководство за упражнения. ВКБООН, 2017. https://www.unhcr.org/bg/wp-content/uploads/ sites/18/2019/08/PDF-BG-Activity-Guide-12-15.pdf, 13.05.2021, c. 8.

14. Да преподаваме за бежанците. Възраст 15 - 18. Ръководство за упражнения. ВКБООН, 2017. https://www.unhcr.org/bg/wp-content/uploads/ sites/18/2019/08/PDF-BG-Activity-Guide-15-18.pdf, 13.05.2021, c. 2 - 3.

\section{ЛИТЕРАТУРА}

ВАСИЛЕВ, В. А. ДЖАЛДЕТИ, 2018. Рефлексията - типове и механизми на осъществяването й. В: Книга за рефлексията. Пловдив: П. Хилендарски.

КОЛЕВА, И., 2011. Етнопсихологически модел на процеса на образователно взаимодействие (рефлексивни аспекти). В: Съвременна хуманитаристика. Бургас: БСУ. 
ЧАВДАРОВА-КОСТОВА, С., 2019. Приобщаване чрез образование и идентичностни проявления. В: Научни и практически аспекти на приобщаващото образование. София: Св. Климент Охридски.

\title{
REFERENCES
}

CHAVDAROVA-KOSTOVA, S., 2019. Priobshtavane chrez obrazovanie i identichnostni proiavlenia. V: Nauchni I prakticheski aspekti na priobshtavashtoto obrazovanie. Sofia: Sv. Kliment Ohridski.

KOLEVA, I., 2011. Etnopsihologicheski model na protsesa na obrazovatelno vzaimodeystvie (refl eksivni aspekti). In: Savremenna humanitaristika. Burgas: BSU.

VASILEV, V., DJALDETI, A., 2018. Reflection - types and mechanisms of its realization. In: Kniga za reflexiata. Plovdiv: P. Hilendarski.

\section{THE REFLECTIVE APPROACH TO THE DEVELOPMENT OF PERSONAL AND SOCIAL COMPETENCES THROUGH LEARNING CONTENT IN THE CONTEXT OF THE REFUGEE PROBLEM FIELD}

\begin{abstract}
A contemporary challenge for Bulgarian teachers is the presentation of learning content related to the refugee flows and the formation of personal and social competences in the context of intercultural education, aiming at awareness of the importance of the topic of migration in individual, community, national and international context. The reflective approach seems to be extremely appropriate for understanding the importance of this type of knowledge in terms of global migration processes, not only by students but also by teachers who have a wealth of opportunities to inform children and develop attitudes towards the issue within class activity, hour of class, extracurricular and out-of-school activities.

Keywords: personal and social competences; refugees; reflection
\end{abstract}

\section{Prof. Siyka Chavdarova-Kostova, DSc. ORCHID ID: 0000-0002-4380-3239}

Web of Science Researcher ID: AAL-2824-2021

Faculty of Pedagogy

University of Sofia Sofia, Bulgaria E-mail: s.chavdarovakostova@fp.uni-sofia.bg 